\title{
Synthesis of Copper-Nickel Nanowires by Two-Step Method
}

\author{
Ma. Shanlene D. C. DelaVega ${ }^{a}$ Mary Donnabelle L. Balela ${ }^{b}$ \\ Sustainable Electronic Materials Group, Department of Mining, Metallurgical and Materials Engineering, University of the Philippines, \\ Diliman, Quezon City 1101, Philippines
}

\begin{abstract}
Copper ( $\mathrm{Cu}$ ) nanowires were successfully coated with nickel (Ni) using a simple, low-temperature, twostepsolution process. The effect ofdifferent types of solvent, e.g. ethylene glycol and water,on the deposition of Ni on $\mathrm{Cu}$ was investigated using a scanning electron microscope (SEM), coupled with energy dispersive X-ray spectrometer (EDX). On the other hand, the composition of the nanowires was determined by X-ray diffraction (XRD). Smoother $\mathrm{Cu}-\mathrm{Ni}$ nanowires were produced using ethylene glycol due to better dispersion of $\mathrm{Cu}$ nanowires and more controlled $\mathrm{Ni}$ diffusion during coating. This can be attributed to the slower reduction of $\mathrm{Ni}(\mathrm{II})$ ions in ethylene glycol, leading to a more controlled deposition on the $\mathrm{Cu}$ nanowires. The as prepared $\mathrm{Cu}-\mathrm{Ni}$ nanowires were confirmed to be facecentered cubic (fcc) $\mathrm{Cu}$ and fcc Ni. Neither oxides of $\mathrm{Cu}$ nor Ni were present on the nanowires produced.
\end{abstract}

\section{Introduction}

Flexibleelectronic applications in advanced fields, such as wearable electronics, medical implants, solar cells, organic light-emitting diodes (OLEDs), smart glass, and foldable displays, are recently being explored [1-2]. In these applications, it's very important to consider flexible materials with high electrical conductivity, and high transparency[1-3]. Currently, indium tin oxide (ITO) is the most commonly used transparent conducting electrode due to its high transmittance $(>90 \%)$ and low sheet resistances (10 $\Omega$ sq. $^{-1}$ on glass). However, ITO, being a ceramic, is brittle and prone to cracking. The cost of ITO is also high since indium is scarce $(0.05 \mathrm{ppm})$ in the earth's crust [4-5].Cu, next to silver (Ag), has the second highest conductivity among all metals and it is more abundant and cheaper. However, the use of $\mathrm{Cu}$ nanowires in flexible transparent electrodes is limited due to its high susceptibility to oxidation. As a result, its electrical conductivity suffers.Additionally, $\mathrm{Cu}$ is inherently reddish-orange in color, which is not desirable for transparent electronic applications [1]. To address this problem, recent studies propose coating the $\mathrm{Cu}$ nanowires with metals having high resistance to oxidation[12].Coating the $\mathrm{Cu}$ nanowires with $\mathrm{Ni}$ not only improves its resistance to corrosion but also changes its color from reddish-orange to gray[1]. With this, $\mathrm{Cu}-\mathrm{Ni}$ nanowire is a promising candidate for flexible electronic applications.

In this study, $\mathrm{Cu}-\mathrm{Ni}$ nanowires were synthesized in solution bya two-step method. The effect of solvent on the quality of the coated $\mathrm{Ni}$ was investigated. The diameter of the $\mathrm{Cu}-\mathrm{Ni}$ nanowires was observed in SEM. Elemental and phase analyses were performed by EDX and $\mathrm{XRD}$, respectively.

\section{Experimental}

The synthesis was adopted from Wiley et al[1,3] which involved two steps to produce $\mathrm{Cu}-\mathrm{Ni}$ nanowires. First, $\mathrm{Cu}$ nanowires were synthesized in an aqueous solution, followed by Nicoating.

\subsection{Materials}

Copper nitrate hemi (pentahydrate) $[\mathrm{Cu}(\mathrm{NO} 3) 2) \cdot 5 \mathrm{H} 2 \mathrm{O}$, Sigma Aldrich] and nickel chloride hexahydrate [NiCl2.6H2O, Fluka] were used as $\mathrm{Cu}(\mathrm{II})$ and $\mathrm{Ni}(\mathrm{II})$ precursor, respectively.Sodium hydroxide $[\mathrm{NaOH}, \mathrm{RCI}$ Labscan], was added to raise the $\mathrm{pH}$ of the solution. On the other hand, ethylenediamine [EDA, Sigma Aldrich] and poly(vinylpyrrolidone) [PVP, 10,000 MW, Sigma Aldrich], and ethylene glycol [EG, JT Baker] were used as surfactants. Hydrazine [N2H4, $35 \mathrm{wt} \%$, Sigma Aldrich] was employed as reducing agent for both $\mathrm{Cu}(\mathrm{II})$ and $\mathrm{Ni}(\mathrm{II})$.

\subsection{Synthesis of $\mathrm{Cu}$ nanowires}

In a typical experiment, $\mathrm{Cu}$ nanowires were synthesized by mixing $200 \mathrm{~mL}$ of $15 \mathrm{M} \mathrm{NaOH}, 10 \mathrm{~mL}$ of $0.1 \mathrm{M}$ $\mathrm{Cu}(\mathrm{NO} 3) 2 \cdot 5 \mathrm{H} 2 \mathrm{O}, 1.5 \mathrm{~mL}$ of ethylenediamine (EDA), and $0.25 \mathrm{~mL}$ ofN2H4. The mixture was heated at $65^{\circ} \mathrm{C}$ for $5 \mathrm{~min}$ with continuous stirring at $200 \mathrm{rpm}$. Then, the solution was removed from heat and $25 \mathrm{~mL}$ of $0.46 \mathrm{mM}$ PVP solution was gently added into the mixture. The total solution was then placed in an ice bath for $1 \mathrm{~h}$. After $1 \mathrm{~h}$ reaction, the red precipitates were collected and washed

Corresponding author: ${ }^{a}$ delavegams@gmail.com, ${ }^{\text {b }}$ mlbalela1@up.edu.ph 
three times with $3 \mathrm{wt} \% \mathrm{~N} 2 \mathrm{H} 4 \mathrm{aqueous}$ solution. The $\mathrm{Cu}$ nanowires were then stored in a solution containing 1 $\mathrm{wt} \%$ PVP and $3 \mathrm{wt} \% \mathrm{~N} 2 \mathrm{H} 4 \mathrm{aqueous}$ solution to avoid oxidation.

\section{$2.3 \mathrm{Ni}-$-Coating of $\mathrm{Cu}$ nanowires}

$\mathrm{Cu}-\mathrm{Ni}$ nanowires were synthesized by adding 3.66 $\mathrm{mL}$ of $\mathrm{Cu}$ nanowire stock $(1.4 \mathrm{mg} \mathrm{Cu}$ nanowires per 1 mlof $3 \mathrm{wt} \% \mathrm{~N} 2 \mathrm{H} 4)$ solution to $6.6 \mathrm{~mL}$ of $2 \mathrm{wt} \% \mathrm{PVP}$, $0.785 \mathrm{~mL}$ of $0.1 \mathrm{M} \mathrm{NiCl} 2 \cdot 6 \mathrm{H} 2 \mathrm{O}$ in water, and $0.66 \mathrm{~mL}$ of $35 \mathrm{wt} \% \mathrm{~N} 2 \mathrm{H} 4$. The PVP solution is prepared in water or EG. This resulting Cu-Nisolution was sonicated for 15 $\mathrm{s}$ and heated at $80^{\circ} \mathrm{C}$ for $10 \mathrm{~min}$. During the reaction, the dispersed $\mathrm{Cu}$ nanowires became aggregated, floated on the surface of the mixture and changed from red to black, indicating the reduction of $\mathrm{Ni}$ (II) ions on the surface of $\mathrm{Cu}$ nanowires. After the $10 \mathrm{~min}$ reaction, black precipitates were magnetically collected. Similarly, the $\mathrm{Cu}-\mathrm{Ni}$ nanowires were washed three times with $3 \mathrm{wt} \%$ $\mathrm{N} 2 \mathrm{H} 4$ aqueous solution and stored in $1 \mathrm{wt} \% \mathrm{PVP}$ and 3 wt $\%$ N2H4 aqueous solution.

\subsection{Characterization}

Surface morphology of the nanowires was analyzed using scanning electron microscopy (SEM, JEOL 5300). Elemental analysis was performed using energy dispersive $x$-ray spectroscopy (EDX, JEOL 5300). Compositional analysis was done using $\mathrm{X}$-ray diffraction (XRD, Shimadzu XRD-7000).

\section{Results and discussion}

Figure 1 shows the SEM images of $\mathrm{Cu}$ nanowires before and after coating with Ni using two-step method. Originally, the $\mathrm{Cu}$ nanowires have a mean diameter of about $71 \mathrm{~nm}$ and mean length of about $30 \mu \mathrm{m}$. The $\mathrm{Cu}$ nanowires have uniform diameter along its length and exhibit mechanical strength since they remain stable even after several washing. Additionally, the $\mathrm{Cu}$ nanowires appear well-dispersed, suggesting limited agglomeration. High magnification SEM image in the inset of Fig. 1(a) shows that each $\mathrm{Cu}$ nanowires is attached to a spherical particle. This could indicate the the $\mathrm{Cu}$ nanowires grew from the spherical particles, which act as seeds during growth [6].

After coating with $\mathrm{Ni}$, the diameter of the $\mathrm{Cu}$ nanowires significantlyincreased from 71 to 108 and 121 $\mathrm{nm}$ when EG and water were used as solvents for PVP, respectively as seen in Fig. 1(b)-(c). The increase in the average diameter of the nanowires indicates that $\mathrm{Ni}$ was coated on the surface. On the other hand, the smaller and smoother $\mathrm{Cu}-\mathrm{Ni}$ nanowires obtained in the presence of EG in Fig. 1(b) can be attributed to the gradual deposition of $\mathrm{Ni}$ atoms on the $\mathrm{Cu}$ nanowires [7-8]. Additionally, the better dispersion of the initial $\mathrm{Cu}$ nanowires in $\mathrm{EG}$ also contributes to the uniform coating of $\mathrm{Ni}$ on $\mathrm{Cu}$ [7].The reduction of $\mathrm{Ni}(\mathrm{II})$ ions occurs faster in an aqueous solution due to the enhanced oxidation of $\mathrm{N} 2 \mathrm{H} 4$ in water [8]. Consequently, more $\mathrm{Ni}$ atoms are produced at a time leading to non-uniform deposition of $\mathrm{Ni}$ along the wire length. This also explains the presence of spherical particles [see inset of Fig. 1(c)] possibly Ni, attached to the surface of the $\mathrm{Cu}$ nanowires.

The EDX spectra, with the corresponding SEM images, of the $\mathrm{Cu}-\mathrm{Ni}$ nanowires prepared in aqueous and EG solutions are shown in Fig. 2. The compositions of the $\mathrm{Cu}-\mathrm{Ni}$ nanowires produced using $\mathrm{EG}$ were 80.74 wt $\% \mathrm{Cu}$ and $19.26 \mathrm{wt} \% \mathrm{Ni}$, while it is $61.90 \mathrm{wt} \% \mathrm{Cu}$ and $38.10 \mathrm{wt} \% \mathrm{Ni}$ when water was employed. The higher amount of $\mathrm{Ni}$ in the $\mathrm{Cu}$ nanowires formed in water can be attributed to the faster reduction of NI(II) ions, which agrees well with the larger nanowires in Fig. 1(c). It is possible that $\mathrm{EG}$ restrains the diffusion of $\mathrm{Ni}$ on the $\mathrm{Cu}$ nanowires due to its high viscosity. This could lead to a more controlled deposition of $\mathrm{Ni}$ on $\mathrm{Cu}$ nanowires.Consequently, lower amount of $\mathrm{Ni}$ is coated as determined by EDX in Fig. 2.No oxygen was also detected in the $\mathrm{Cu}-\mathrm{Ni}$ nanowires, which indicates that the both oxides of $\mathrm{Cu}$ and $\mathrm{Ni}$ were not present in the nanowires.

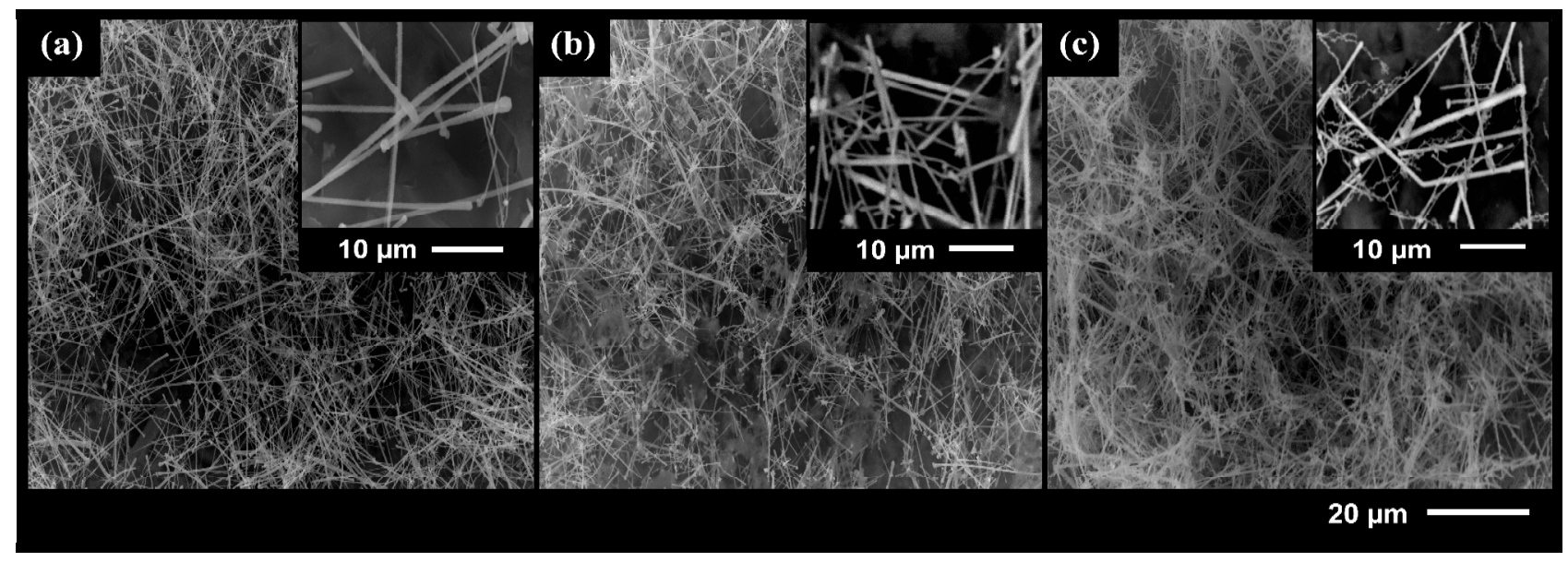

Figure 1. SEM images of $\mathrm{Cu}$ nanowires (a) before and after coating with Ni using (b) EG and (c) water as solvents. 

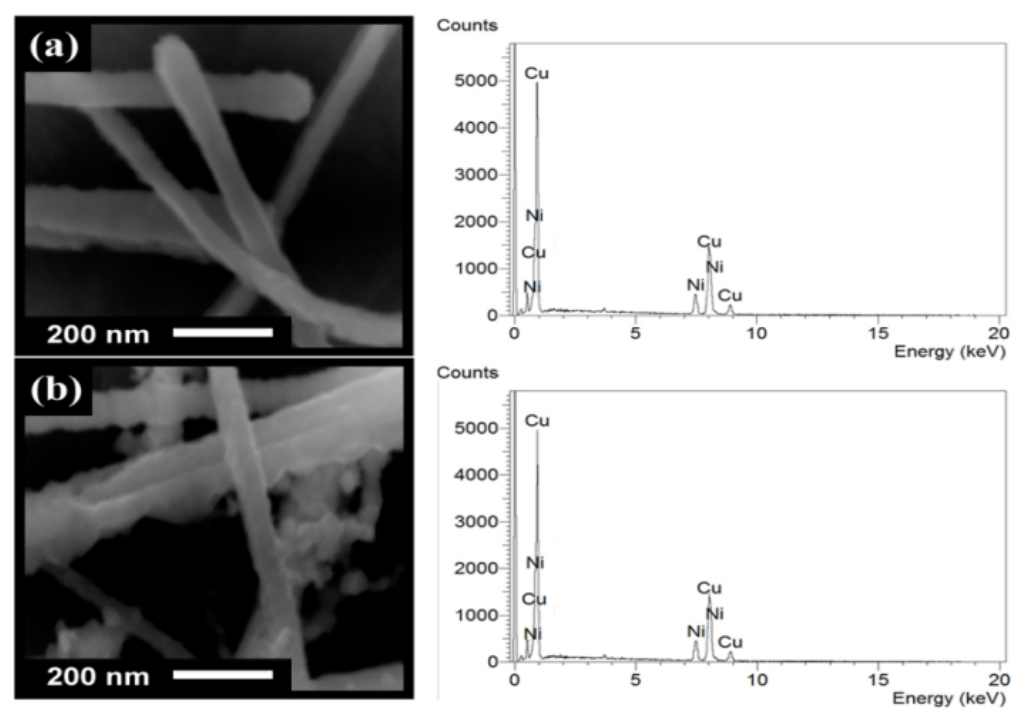

Figure 2. EDX spectra of the $\mathrm{Cu}-\mathrm{Ni}$ nanowires prepared in aqueous and EG solutions with the corresponding SEM images.

Figure 3 shows the corresponding XRD patterns for the $\mathrm{Cu}-\mathrm{Ni}$ nanowires prepared in $\mathrm{EG}$ and water. For $\mathrm{Cu}-$ $\mathrm{Ni}$ in $\mathrm{EG}$, three characteristic peaks were observed at $2 \theta$ equal to $43.38,50.54$ and $74.06^{\circ}$ corresponding to 111 , 200 and 220 peaksof metallic $\mathrm{Cu}$ (JCPDS 04-0836), respectively [9]. Further, peaks at $2 \theta$ equal to 44.58 , 51.84, and $76.34^{\circ}$ are indexed to to the 111,200 and 220 peaksof metallic Ni (JCPDS 04-0850), respectively [10]. Similarly, for $\mathrm{Cu}-\mathrm{Ni}$ formed in water, only peaks attributed to both metallic $\mathrm{Cu}$ and $\mathrm{Ni}$ were observed [910].This suggests that the $\mathrm{Cu}$ nanowires were successfully coated with Ni. Moreover, no peaks due to oxides of $\mathrm{Cu}$ and $\mathrm{Ni}$ were detected on the XRD patterns, which agrees with the EDX results. This also attest to the purity of the $\mathrm{Cu}-\mathrm{Ni}$ nanowires prepared by the proposed method.

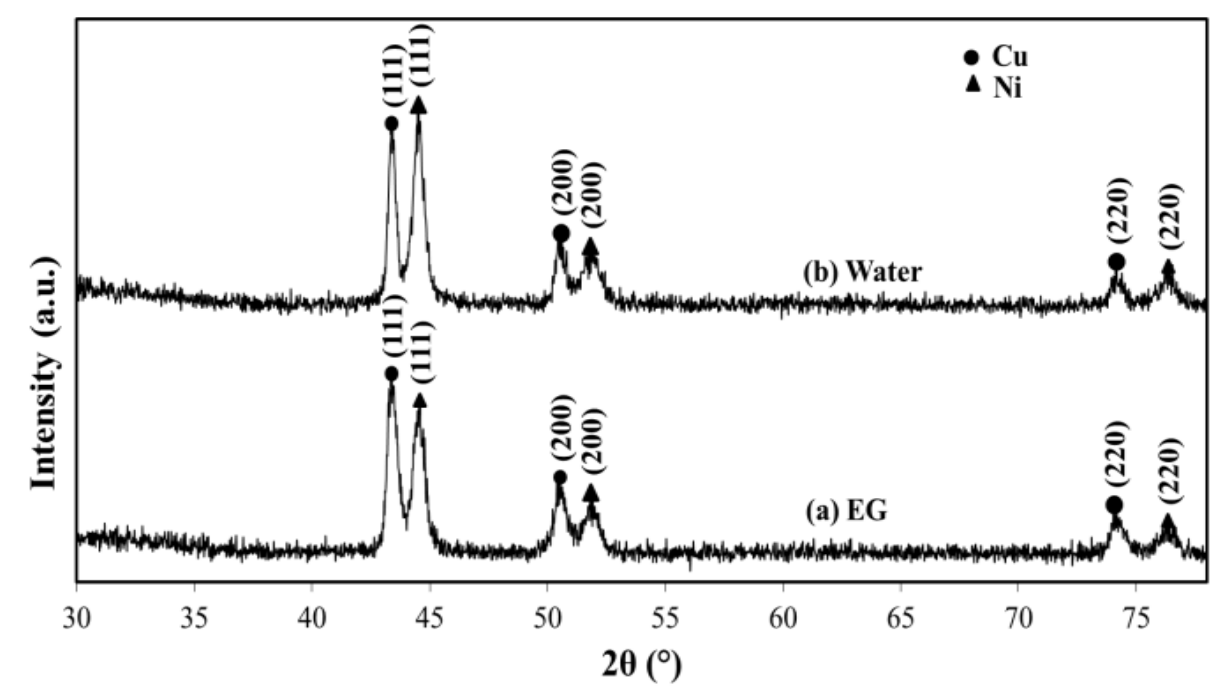

Figure 3. XRD patterns of $\mathrm{Cu}-\mathrm{Ni}$ nanowires prepared using (a) EG and (b) water as solvents.

\section{Conclusion}

$\mathrm{Cu}$ nanowires, about $71 \mathrm{~nm}$ in mean diameter, were successfully coated with $\mathrm{Ni}$ using water and EG as solvents. The mean diameter of the $\mathrm{Cu}$ nanowires was increased to 108 and $121 \mathrm{~nm}$ after coating with $\mathrm{Ni}$ using EG and water, respectively. The use of EG prevents the agglomeration of nanowires and improves dispersion of nanowires. Thus resulted to more controlled Ni coating, which produced smaller and smoother $\mathrm{Cu}-\mathrm{Ni}$ nanowires.
EDX results showed a lower percentage of coated $\mathrm{Ni}$ when EG is used as solvent. This is due to the slower reduction of $\mathrm{Ni}(\mathrm{II})$ ions in EG.As a result, $\mathrm{Ni}$ atoms deposits gradually on $\mathrm{Cu}$ nanowires.XRD patterns of the $\mathrm{Cu}-\mathrm{Ni}$ nanowires revealed peaks of metallic $\mathrm{Cu}$ and $\mathrm{Ni}$ only. Oxides of $\mathrm{Cu}$ and $\mathrm{Ni}$ were not present based from both EDX and XRD results.

\section{Acknowledgement}


The study is supported by the Department of Science of Technology under the Philippine Council for Industry, Energy, and Emerging Technology Research and Development (DOST-PCIEERD) and the Office of the Vice-Chancellor for Research and Development under the PhD Incentive Award.

\section{References}

1. Rathmell, A. R., Nguyen, M., Chi, M., \&Wiley, Nano Lett., 12, 3193-3199 (2012)

2. Song, J., Li, J., Xu, J., \& Zeng, Nano Lett. 14, 62986305 (2014)

3. Wiley, B. J., \& Rathmell, (2013)

4. Ye, S., Rathmell, A. R., Chen, Z., Stewart, I. E., \& Wiley, Adv. Mater. 8, 9673-9679 (2014)
5. Stewart, I. E., Rathmell, A. R., Yan, L., Ye, S., Flowers, P. F., You, W., \&Wiley, Nanoscale 6, 5980-5988 (2014)

6. Ye, S., Rathmell, A. R., Stewart, I. E., Ha, Y. C., Wilson, A. R., Chen, Z., \& Wiley, Chem. Commun. 50, 2562-2564 (2014)

7. Gong, C., Tian, J., Zhang, J., Zhang, X., Yu, L., \& Zhang, Mater. Res. Bull. 45, 682-687 (2010)

8. Ai, D., \& Kang, Mater. Trans. 47, 2056-2059 (2006).

9. International Center for Diffraction Data. JCPDS 040836. Prentice Hall, 2004. http://www.pearsonstudium.de

10. International Center for Diffraction Data. JCPDS 040850. Prentice Hall, 2004. http://www.pearsonstudium.de 